\title{
CREATIVITY AND PROBLEM SOLVING: an experiment with Design students
}

\author{
Gabriela Trindade Perry \\ Universidade Federal do Rio Grande do Sul \\ gabriela.perry@ufrgs.br \\ Suely Dadalt Fragoso \\ Universidade Federal do Rio Grande do Sul \\ suelyfragoso@ufrgs.br \\ Eduardo Cardoso \\ Universidade Federal do Rio Grande do Sul \\ eduardo.cardoso@ufrgs.br \\ Airton Cattani \\ Universidade Federal do Rio Grande do Sul \\ $\underline{\text { aacc@ufrgs.br }}$
}

\begin{abstract}
Functional fixedness (FF) is a concept from Gestalt Theory that describes how subjects tend to be fixated on previously known patterns. FF hinders creativity and diminishes problem solving abilities. Therefore, the nature of design requires that its practitioners exhibit less FF than the general population. In this article, we describe the results of an experiment that intended to verify whether formal Design education lessens the effects of FF on problem-solving. To this end, 75 students from the $1^{\text {st }}(n=40)$ and $3^{\text {rd }}(n=35)$ semesters of a Graduate Design Course were asked to solve the 2 variations of Duncker's Box Problem (1945). Two other variations were added, regarding the influence of dealing with real materials or visual representations (drawings). The study compared the strength of FF in freshmen with $3^{\text {rd }}$ semester students in 4 situations: Duncker's (a) inside and (b) outside the box and (c) concrete objects and (d) 2D visual representations. Results suggest variations in the strength of FF on problem-solving when using concrete materials in comparison to with visual representations (drawings). No significant difference in the results obtained by the two populations was found, apart that the $3^{\text {rd }}$ semester students were more likely to present the solutions they proposed in ways that can be interpreted as attempts to overcome FF.
\end{abstract}

Keywords: Functional fixedness, creativity, problem solving.

\section{INTRODUCTION}


Functional fixedness (FF) is a phenomenon that reflects perceptual processes: a subject $S$ perceives the elements of a given problem in such a way that it impairs him to find the (or a) solution. This phenomenon was first described by Duncker (1945, p. 85 ) in the following way:

"A chimpanzee who stands in need of a stick (something long, firm) sometimes has difficulties in recognizing the stick in a branch still growing on the tree [...]. On the tree it is a "branch", a part of the visual figural unit "tree", and this part-character- more generally, this "fixedness" - is clearly responsible for the fact that to a search for something like a stick, the branch on the tree is less "within reach" than the branch on the ground. What we just named "fixedness" may, however, be conditioned functionally as well as by such factors of visual organization. For instance, a stick that has just been used as a ruler is less likely to appear as a tool for other purposes than it would normally be."

Duncker's idea has implications For Problem Solving Theory, in that it argues for a fundamental role for past experience on the range of strategies taken into consideration during problem solving (Birch \& Rabinowitz, 1951). The difference between reproductive and productive thinking elaborated by Maier (1930 apud Birch \& Rabinowitz, 1951) helps understanding the issue. Reproductive thinking would be favored when there are stimulus equivalences between the current problem/situation and past experiences. Productive thinking, on the other hand, happens when "past experience is re-patterned and re-structured to meet current demands, and is thus the counterpart of reasoning" (Maier, 1930 apud Birch \& Rabinowitz, 1951); i.e. there are not stimulus equivalences between the current problem/situation and past experiences.

Duncker designed a series of experiments to verify if Functional Fixedness was really the case - if it was really a perceptual phenomenon, it would be widespread amongst the population. His premise was that if solving a specific problem requires perceiving and using well-known, daily used objects in an unusual way, subjects would have more difficulty to reach the solution when those objects are presented as commonly encountered in their day-to-day context, than when the regular function of the object is not presented as part of the problem. The problems proposed in Duncker's experiments include gimlets, pliers, matches, pendulums, paperclips, candles and boxes (Duncker, 1945, p. 86). The experiments consisted of static-group comparisons of the type which Campbell \& Stanley (1960) classify as a preexperimental design, as differences inside the groups are not controlled. Adamanson (1952) and Birch \& Rabinowitz (1951) also noted that Duncker's experiments' conditions were "poorly specified" and therefore his results could not be generalized. Additionally, Duncker's groups for the candle problem were composed of only 7 subjects (1945, p.88), which also compromises the generalization of his results. However, Duncker's results should not be disregarded because of sample size. He found out that, under those experimental conditions, "the object which is not fixed is almost twice as easily found as the object which is fixed" $(1945$, p.88). One of Duncker's most cited experiments is the Box Problem, which we present in the next sub-section.

\subsection{Duncker's Box Problem}


The Box Problem involves the use of a covered wall, a table, three small candles, three little boxes, tacks and some other random objects. Those were arranged in two different set ups:

In the setting 1 the three boxes were filled with experimental material: in one there were several thin little candles, tacks in another, and matches in the third. In 2., the three boxes were empty and the objects. Thus function 1 (f1): "container". Function 2 (f2): "platform" (on which to set things). (Duncker, 1945)

Subjects were asked to attach the candles to the covered wall so that they could be lit without dripping wax onto the table below. The solution consisted in using a tack to fasten each box to the wall and use the boxes as platforms for the candles. Figure 1 illustrates the two enunciations of this problem.
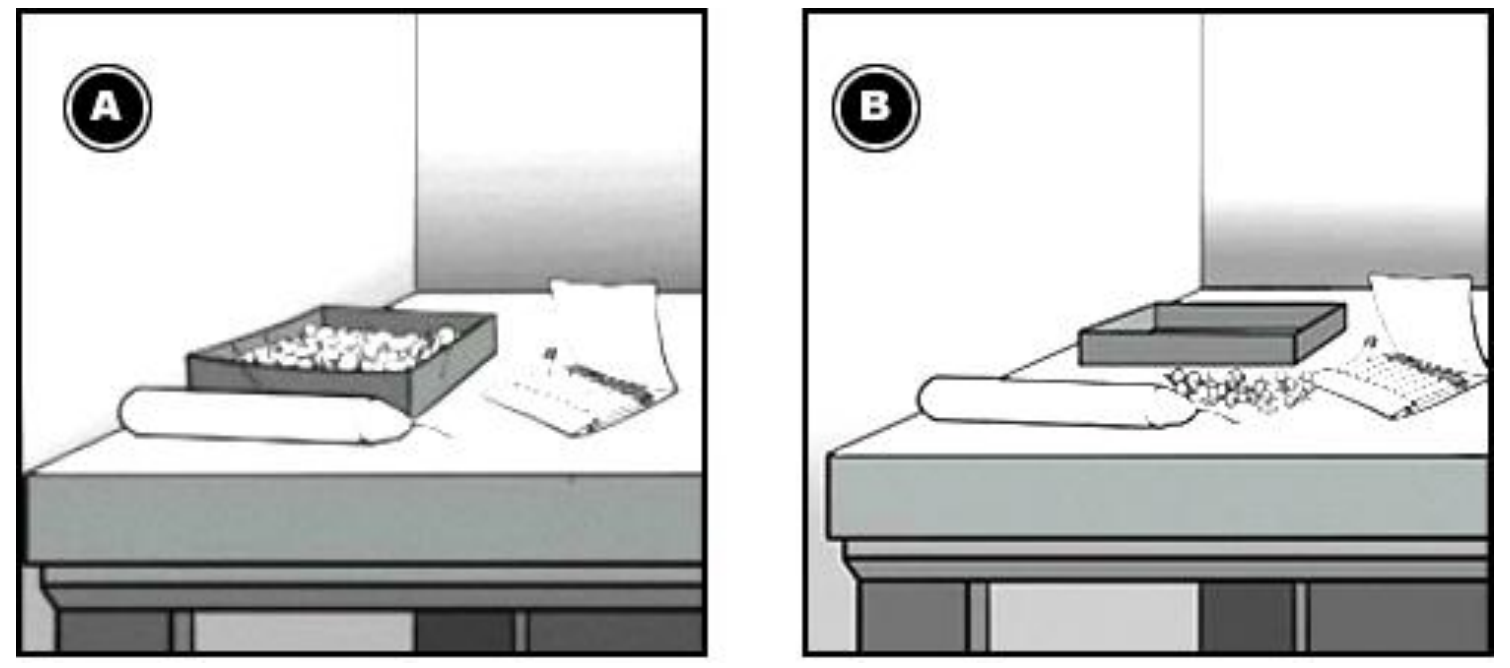

Figure 2 - Duncker's candle problem. Source: http://tinyurl.com/kht8rhc

Adamson (1952) repeated Duncker's experiment with the Box Problem with 57 subjects (students from the Psychology department). He used exactly the same settings, instructions and the general experimental design - which, as said before, does not control for differences between groups. Adamson's conclusions were the same as Duncker's (Adamson, 1951, p. 289):

"FF results from pre-utilization. The performance of the experimental group was markedly inferior to that of the control with respect both to the number of solutions obtained and the time required to reach solutions. Prior usage of the boxes as containers inhibited their being used as platforms."

\subsection{Other experiments regarding FF}

Birch \& Rabinowitz (1951) readdressed the idea of FF under more appropriate experimental settings, reaching the same conclusion as Duncker. Their experiments were based on Maier's two-cord problem (Maier, 1931 apud Birch \& Rabinowitz, 1951), in which

"the [subject] $S$ is required to tie together the free ends of two cords which are suspended from the ceiling to the floor of a corridor. The distance between the two cords is such that the $S$ cannot reach one cord if the other is held. In our arrangement the problem could be solved only if the $S$ would tie a weight to the end of one of the strings and thus convert 
it into a pendulum which could be set swinging and then be caught on its upswing while the stationary cord was held."

A number of objects were scattered around the room, including an electrical switch and a plier (the only one with enough weight to make a pendulum). Figure 1 illustrates the problem situation.

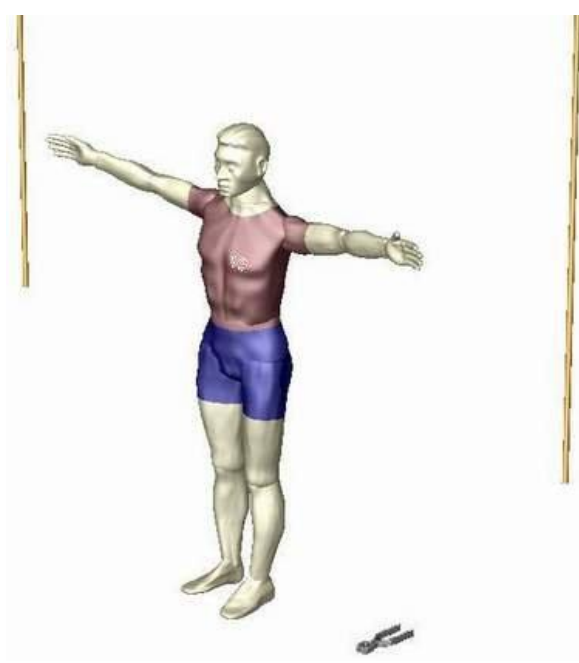

Figure 1 - Maier's two-cord problem. Source UNCG DCL (2013).

The authors were trying to verify whether previous experiences (from pretraining tasks) with the "weight-objects" would influence the ability to solve the problem. No significant difference was found for individuals with any pre-training, which used both objects equally. Subjects who had received pre-training with one or the other object favored the use of that one as their "weight-object" (Birch \& Rabinowitz, 1951).

Adamson \& Taylor (1954) replicated Birch \& Rabinowitz (1951) experimental conditions of Maier's two-cord problem, to verify the influence of elapsed time since the usage of the "weight-objects" (a switch and a plier). A group of 65 undergraduate students in general psychology were divided in 5 sets. All were submitted to pretraining (constructing an electrical circuit using either a relay or a switch), followed to increasing intervals of "uncontrolled activity" after which they were invited to resolve the Cord Problem. Intervals varied between 1 minute and 1 week.

Several other experiments have tested side hypothesis to FF - time constraints, verbal marks etc. Glucksberg (1962) returned to the Box Problem and investigated the hypothesis of "drive influence" on problem solving using a $2 \times 2$ factorial design ( 2 groups; 2 conditions). A total of 128 subjects were required to solve the Box Problem, with varying drive degrees (that is, varying degrees of stimuli to solve the problem). Drive was controlled as time and money rewards: subjects of the low-drive group were not promised any type of reward for solving the problem, whilst the high-drive group was stimulated by the promise of money rewards to the top $25 \%$ faster solvers. Interestingly, subjects within the high-drive-"tacks-in-the-box" group had more failures than the low-drive-"tacks-in-the-box", leading to the conclusion that a high drive impairs problem solving. 
Glucksberg \& Weisberg (1966) hypothesized that problem-solving performance would vary according to labeling (which would elicit properties of the stimulus situation). A group of 165 undergraduate college students served as subjects on a experiment which presented the candle problem in 3 different labeled illustrations: in the $1^{\text {st }}$, all objects in the picture were labeled; in the $2^{\text {nd }}$, no object was labeled and in the $3^{\text {rd }}$ there was just one label, (the word "TACKS" printed in capital block letters on the side of the box). They found significant differences between each group.

\section{Readdressing the Box Problem: FF, Design Education and Creativity}

As a perceptual phenomenon related to problem solving, FF can play an important role in Design practices. Accepting previous research findings about FF as our departure point, we performed an experiment to verify the hypothesis that the formal study of Design can lessen the occurrence of this phenomenon. To this end, seventy five students from the $1^{\circ}(n=40)$ and $3^{\circ}(n=35)$ semesters from two Graduation courses (Product Design and Visual Design) from the same university (UFRGS Universidade federal do Rio Grande do Sul) were asked to solve 2 variations of Duncker's (1945) Box Problem. Our settings were similar to Duncker's, with two main differences: first, only one candle and box was given to each subject (redundancy was not considered necessary). Second, we worked with two different presentations of the task: one with physical materials (a real box, candle and tacks) and the other with drawings of those elements.

The rationale behind having a pencil-and-paper version is that drawing sketching - is the preferred design tool. At the time ideas are generated, designers use sketches - fast, low-detail drawings - to communicate with each other and to elaborate on problem solving (Verstijnen et al., 98; Kavakli, 98; Goel, 1995). Cross (1999) argues that sketching allows designers to deal with different levels of complexity and abstraction simultaneously, that is, it facilitates thinking about the whole and about its parts at the same time.

\subsection{MATERIALS AND METHODS}

A total of 75 students at two different stages of two Design Courses (Product Design and Visual Design) were randomly assigned to one of 8 groups. This was done by asking the students of each stage to draw a numbered paper from a casket. Numbers varied between 1 and 4 to each group, corresponding to: 1) concrete objects - tacks inside the box; 2) concrete objects - tacks outside the box; 3) drawing - tacks inside; 4) drawing - tacks outside. Distribution is shown in Table 1.

Table 1 - Amount of students in each experimental group. Created by the authors from research data.

\begin{tabular}{|c|c|c|c|c|c|c|c|c|}
\hline \multicolumn{4}{|c|}{ Lectures on Design ( $3^{\circ}$ semester) } & \multicolumn{4}{|c|}{ Introduction to Design ( $1^{\circ}$ semester) } & \\
\hline \multicolumn{2}{|c|}{ Tacks inside } & \multicolumn{2}{|c|}{ Tacks outside } & \multicolumn{2}{|c|}{ Tacks inside } & \multicolumn{2}{|c|}{ Tacks outside } & \\
\hline Drawing & $\begin{array}{l}\text { Concrete } \\
\text { materials }\end{array}$ & Drawing & $\begin{array}{l}\text { Concrete } \\
\text { materials }\end{array}$ & Drawing & $\begin{array}{l}\text { Concrete } \\
\text { materials }\end{array}$ & Drawing & $\begin{array}{l}\text { Concrete } \\
\text { materials }\end{array}$ & SUM \\
\hline 8 & 7 & 12 & 8 & 11 & 11 & 10 & 8 & 75 \\
\hline \multicolumn{4}{|c|}{35} & \multicolumn{4}{|c|}{40} & \\
\hline
\end{tabular}


The number of subjects on each group varied according to the total number of students enrolled in each class, as well as the number of students present in the day of the experiment.

Three professors and four volunteer students (that were not part of either group) acted as mediators. The experiment took place in three $25 \mathrm{~m}^{2}$ rooms: in the $1 \mathrm{st}$ room, students were asked to wait to perform the task; in the $2^{\text {nd }}$ room, they actually performed the task and in the $3^{\text {rd }}$ room they were asked to describe the task, in a group interview. One professor was responsible for the activities in each room; the volunteer students went from room to room to provide help when needed (measuring time, storing materials, mounting the set, directing students from one room to another and photographing the process and the solutions proposed). The 8 groups went through the 3 stages of the experiment in an interval of 2 hours (from $18 \mathrm{~h} 30$ to 20h30). Therefore, experimental settings had to be quickly reassembled after each group and all staging had to be perfectly synchronized.

In the first room, subjects were informed that they were to participate in an experiment on creativity and problem-solving, in which they would be asked to perform a task that would mimic a design situation. They were also informed that the task was part of the curricula of both classes, so they would get credits for participation as far as they followed the instructions.

In the second room, students were presented to one of the 4 variations of Dunker's Box Problem. In the first variation, students encountered a piece of balsa wood glued to a wall, at the intersection with a table. On the table there was a piece of paper with a question, a candle and a closed matchbox, with tacks and matches inside. The second variation was practically the same, but the box was empty and the tacks and matches were placed on the table. Figure 3 depicts this situation. Variations 3 and 4 corresponded to the drawings of the $1^{\text {st }}$ and $2^{\text {nd }}$ set ups, with the question as heading (Figure 4).

Students were positioned away to each other, or sat with their backs turned to each other when distance was not possible. They were instructed not to turn the instructions paper and read it before signaled to do so; not to look at other students and to call someone when they thought they have reached a solution. Instructions' wording was the same for all groups (Figure 4). 


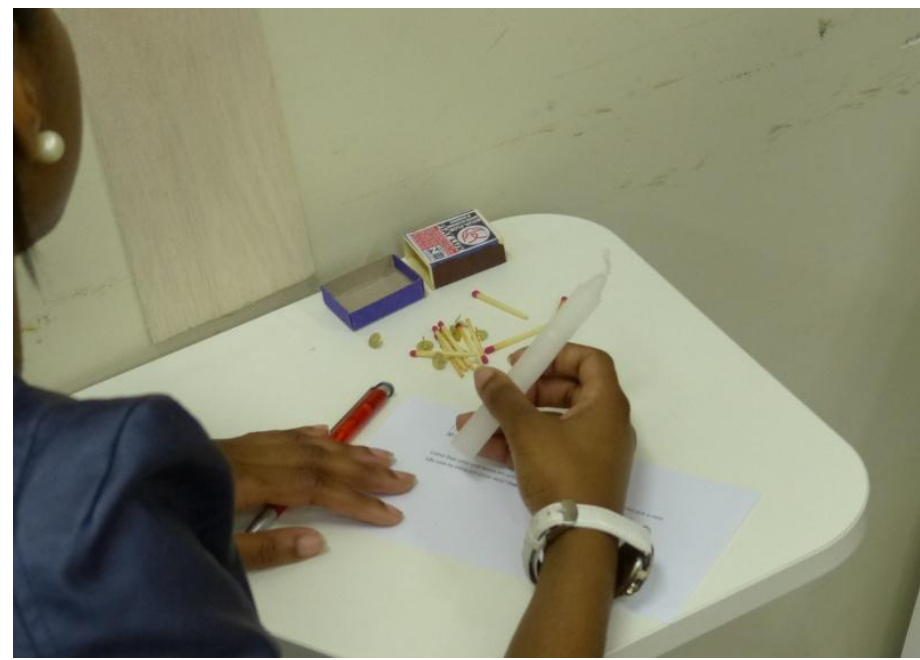

Figure 3 - Student with concrete materials and tacks outside the box.

How would you attach a lighted candle to the balsa wood, preventing the wax to fall on the table? Draw or describe your solution.
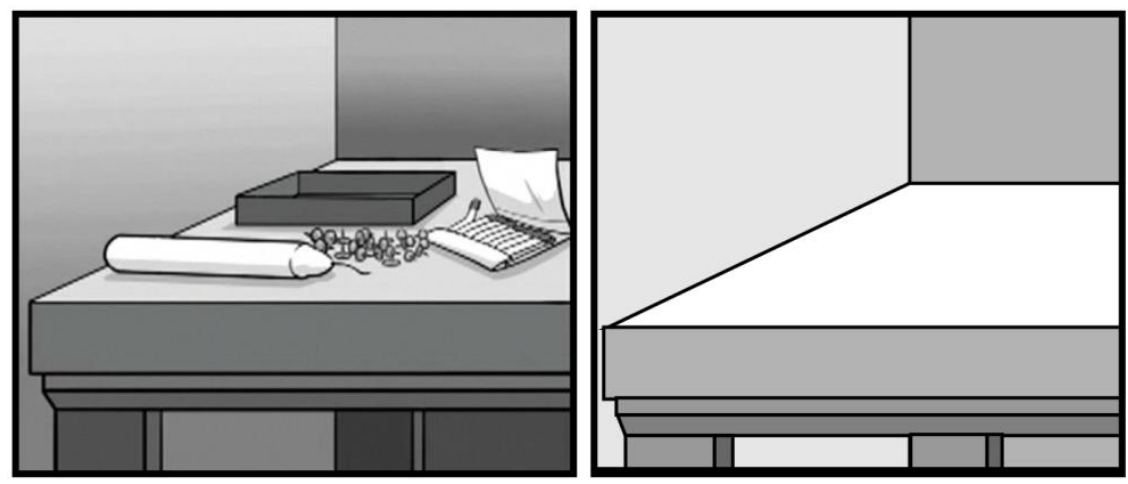

Figure 4 - The assignment and the drawing sheet.

Following Duncker's parameters, only one solution was admitted to be right; the one shown in Figure 5.

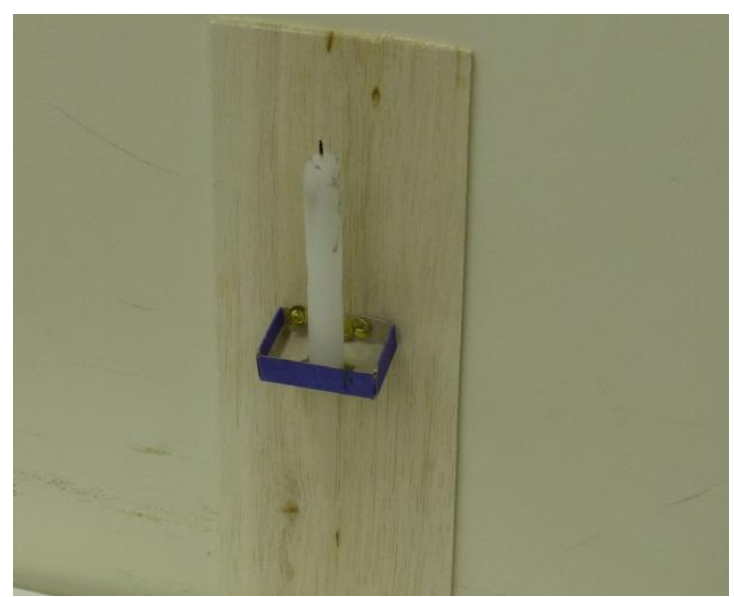

Figure 5 - The only solution considered to be right. 
All procedures, materials and the wording of the instructions had been formerly tested with a different group of students in another class. Students who participated in the pilot study were asked not to talk about it with other colleagues, as it was a part of a research activity.

\section{RESULTS}

Overall, students did not manifest doubts or difficulties with any of the 4 settings (concrete objects or drawing; tacks inside or outside the box). However, a number of unusual solutions were found, as the Figure 6 shows. A few of them could eventually have been argued to be adequate, but their effectiveness was highly questionable. Therefore, all of these variations were considered wrong.
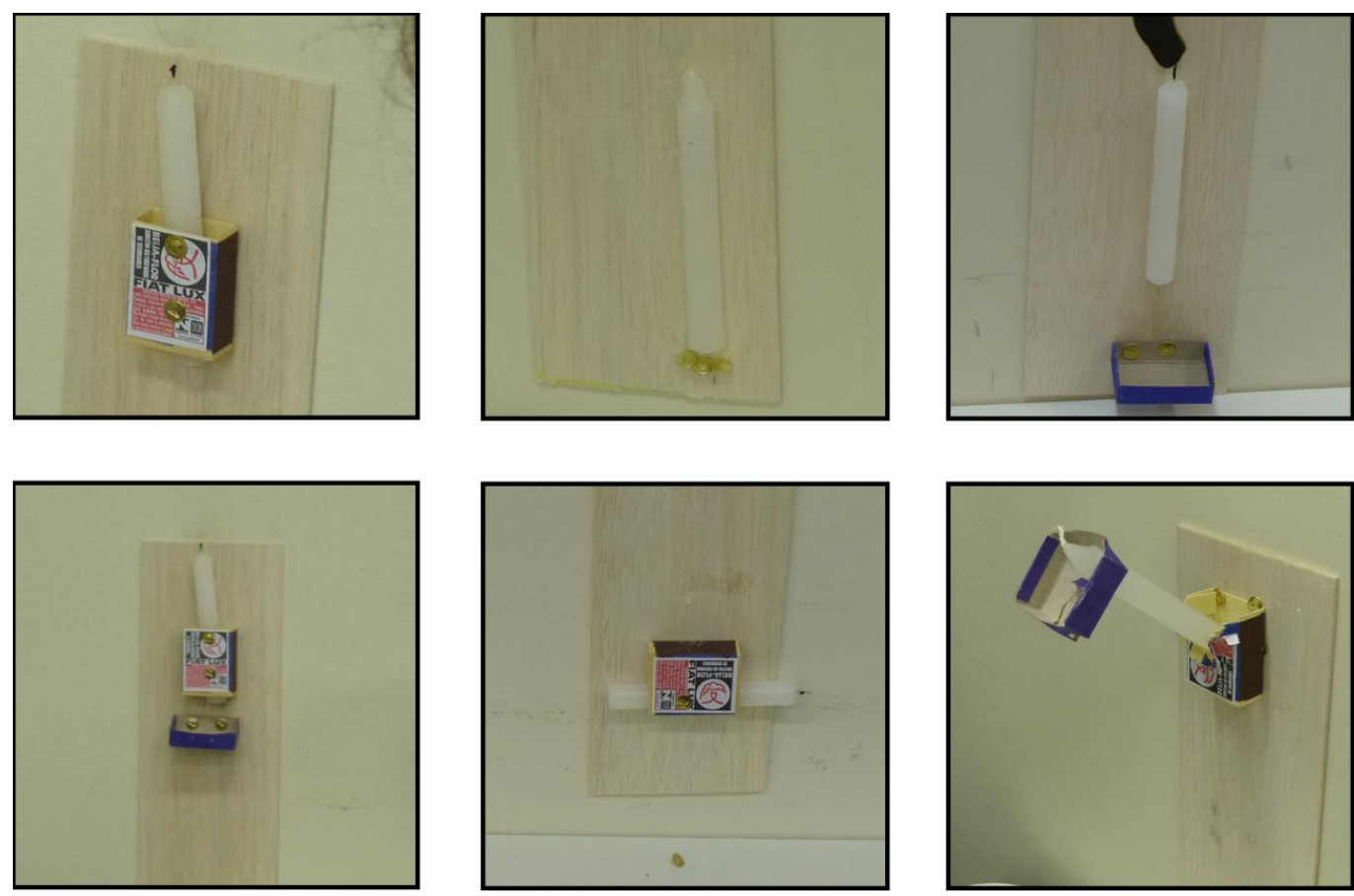

Figure 6 - A variety of creative solutions, that did not satisfy the conditions and were considered wrong.

We registered time-to-answer (Table 2 ) and correctness of the solutions (Table 3). All possible variables were binary (there were only two possible answers to each); therefore we chose to verify the hypothesis of influence of students' semester on correctness with a binary regression model (Kutner et al, 204). These models are suited for cases where you have explanatory variables of any kind (interval, categorical, ordinal) - the "right side" of the equation, the independent variables - and you use them to predict the outcome of a binary variable - "the left side", the " $y$ ", the dependent variable.

Table 2 - Average and (standard deviation) of time-to-answer, in seconds.

\begin{tabular}{c|c|c|c|c|c|c|c}
\multicolumn{3}{c|}{$3^{\text {rd }}$ Semester Students } & \multicolumn{3}{c}{$1^{\text {st }}$ Semester Students } \\
\hline \multicolumn{2}{c|}{ Tacks inside } & \multicolumn{2}{|c|}{ Tacks outside } & \multicolumn{2}{|c}{ Tacks inside } & \multicolumn{2}{c}{ Tacks outside } \\
\hline Drawing & $\begin{array}{l}\text { Concrete } \\
\text { materials }\end{array}$ & Drawing & $\begin{array}{l}\text { Concrete } \\
\text { materials }\end{array}$ & Drawing & $\begin{array}{l}\text { Concrete } \\
\text { materials }\end{array}$ & Drawing & $\begin{array}{l}\text { Concrete } \\
\text { materials }\end{array}$ \\
\hline 372 & $475(132)$ & 406 & $460(200)$ & 343 & $329(119)$ & $345(59)$ & $381(323)$
\end{tabular}


Table 2 indicates that subjects dealing with concrete materials in $3^{\text {rd }}$ semester needed more time to find the solution than those working with drawings.

Table 3 - Correctness of solutions - percentage and (number of subjects). $3^{\text {rd }}$ Semester Students

$1^{\text {st }}$ Semester Students

\begin{tabular}{c|c|c|c|c|c|c|c}
\hline \multicolumn{2}{c|}{ Tacks inside } & \multicolumn{2}{c|}{ Tacks outside } & \multicolumn{2}{c|}{ Tacks inside } & \multicolumn{2}{c}{ Tacks outside } \\
\hline Drawing & $\begin{array}{l}\text { Concrete } \\
\text { materials }\end{array}$ & Drawing & $\begin{array}{l}\text { Concrete } \\
\text { materials }\end{array}$ & Drawing & $\begin{array}{l}\text { Concrete } \\
\text { materials }\end{array}$ & Drawing & $\begin{array}{l}\text { Concrete } \\
\text { materials }\end{array}$ \\
\hline $50 \%(8)$ & $50 \%(6)$ & $64 \%(11)$ & $29 \%(7)$ & $0 \%(10)$ & $60 \%(10)$ & $40 \%(10)$ & $57 \%(17)$
\end{tabular}

Table 3 indicates that the number of $3^{\text {rd }}$ semester students who reached the solution with concrete materials was smaller than that of $1^{\text {rd }}$ semester students. They did better than freshmen when drawing. The students who gave incorrect answers were, in most of the cases, students who gave "almost-correct" answers (Figure 6). In the third stage of the experiment, during the group interviews, these solutions were described enthusiastically and the other members of the group at times considered them to be more appropriate than the expected solution in that they were more 'creative'. The correct solution was said to be "too obvious" by some students who did not present it. This can be understood as a sign that these students were aware of this solution, but trying to find an alternative to it. If this is the case, these students would have been aware of the existence of FF, despite not having been presented to the concept. Their failure would be the result of a struggle to circumvent the fixedness of the "traditional" solution. On the other hand, those explanations could have been created a posteriori, as several students (particularly those at the $3^{\text {rd }}$ semester of the Graduation Courses) were notably competent at verbally "defending" their solutions, even when they were clearly inappropriate. Freshmen were more willing to accept that they had failed at the task than $3^{\text {rd }}$ semester students.

None of the freshmen who were presented to the problem in the form of drawing and with the tacks inside the box found the correct answer, or an "almostcorrect" alternative solution. Table 4 shows the correlations between pairs of variables. The goal of performing this pairwise correlation is to see which of the variables would be a good predictor.

Table 4 - Correlations between pairs of variables.

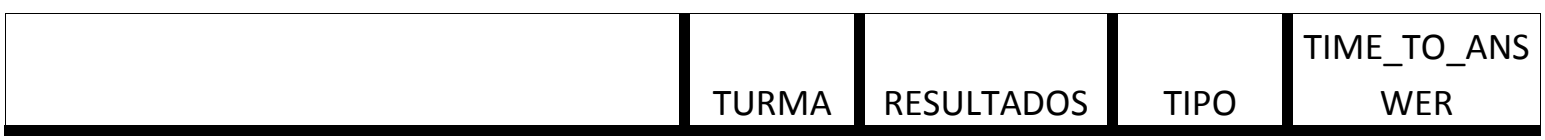




\begin{tabular}{|l|l|r|r|r|r|}
\hline \multirow{2}{*}{ TURMA } & Pearson Correlation & 1 &, 112 &, 085 &, 214 \\
\cline { 2 - 5 } & Sig. (2-tailed) & &, 365 &, 493 &, 079 \\
\hline \multirow{2}{*}{ RESULTADOS } & Pearson Correlation & & 1 &,- 062 &,- 067 \\
\cline { 2 - 5 } & Sig. (2-tailed) & & &, 614 &, 589 \\
\hline \multirow{2}{*}{ TIPO } & Pearson Correlation & & & 1 &,- 120 \\
\cline { 2 - 5 } & Sig. (2-tailed) & & & &, 331 \\
\hline \multirow{2}{*}{ TIME_TO_ANSWER } & Pearson Correlation & & & & 1 \\
\cline { 2 - 5 } & Sig. (2-tailed) & & & & \\
\hline
\end{tabular}

In Table 4 it is possible to see that no pair of variable had a significant correlation $(p<0.05)$. This suggests that the model of logistic regression will not have enough power to predict when a given student will give a correct answer. Even with this prognostic, we ran the Binary Logistic Regression, and used as predictor variables "class/semester", "time to answer" and "group" (tacks inside; tack outside; drawings inside; drawings outside). The model without any predictor variables explained $56 \%$ of the results (the variable "result", which could be either "correct" or "incorrect"). With the predictor variables, the model explained $63 \%$ of the results, a value we consider very low.

\section{CONCLUSION}

Our findings did not follow those of the reviewed literature: we found no differences between students' ability to solve the Box Problem when presented with the two variations proposed by Duncker (1945): tacks inside versus outside the box, using concrete materials. This can be attributed to the fact that binary logistic models demand larger samples, that is, more data, from more subjects. However, none of our groups was smaller than Duncker's.

On the other hand, our results indicate possible variations in the strength of FF on problem-solving when using concrete materials or visual representations (drawings), but without clear patterns or tendencies. We consider this result to be important enough to motivate further studies.

Perhaps the Box Problem is, nowadays, too simplistic and not perceived as challenging by the students. Therefore, they can have either not paid much attention to it or failed to present the correct solution because they believed it to be obvious and believed that, as Design students, they were required to be "more creative" than that. Although FF is a subject matter which is related to problem solving and therefore with creativity, this experiment does not accommodates "almost-correct" answers. The authors have discussed if some of the answers shown in Figure 6 could be considered correct solutions, in that they would have satisfactorily fulfilled the challenge's requirements. We agreed that, as our study was intended to be a comparison with the findings reported in previous literature, none of these alternative solutions could be considered "as correct as" the expected one. For calculations, we considered these as wrong answers - that is why one of the groups had no correct answers. However, all viable (or nearly viable) solutions were marked as "almost- 
correct" in our data sets and tabulation. This is important because, when designing, there is not a single, optimum solution, but a range of solutions, with pros and cons. For example, Herbert Simon (1996), in a very famous definition about Design, says "The natural sciences are concerned with how things are. Design, on the other hand, is concerned with how things ought to be". Updating this statement to our contemporary knowledge of the social role of Design, we would say: Design is concerned with how things can - and could - be.

Finally, we would like to expose some limitations of our study. Some of those were foreseen, some were not. The most severe limitations concern (1) the conditions of the experimentation; (2) students motivation; (3) the sampling and (4) the experimental design.

The conditions were not ideal: it would have been better if each student could perform the task alone with the experimenter, instead of several of them being present in the same room at the same time. Also, students had to wait in the first room before proceeding to the second room for the experiment. The waiting period varied from 1 minute (for Group 1) to 60 minutes (for Group 4). Students who waited longer engaged in other activities, including a heated debate of university policies, which can have influenced them towards being more defensive of their solutions in the interview.

Regarding the motivation, we considered that giving credits for performing this task might influence the behaviour of the students positively. On the one hand, this includes a threat to the study's inner validity (Campbell \& Stanley, 1960), on the other, according to Glucksberg, this could have a negative influence on the subjects' performance. The ideal setting would be if the university had a kind of pool of research subjects (as some universities have), were students would voluntarily join aiming to receive credits for extra-class assignments. This would also allow for a more varied and larger sample. In the absence of this possibility, we had to resort to the use of a convenience sample - our own students. Further studies will be broader, more descriptive of the problem and allow for more effective comparisons of the performance and results if the performance of Design students could be compared with that of a group with a different profile and background (maybe students from a pure science course), for example. We aim to collect this data in future studies.

\section{REFERENCES}

ADAMSON, R.E., 1952. Functional fixedness as related to problem solving; a repetition of three experiments. Journal of experimental psychology, 44(4), p.288-291.

ADAMSON, R.E. \& TAYLOR, D.W., 1954. Functional fixedness as related to elapsed time and to set. Journal of experimental psychology, 47(2), p.122-126.

BIRCH, H. G., \& RABINOWITZ, H. S. 1951. The negative effect of previous experience on productive thinking. Journal of experimental psychology, (41), 121-125.

DUNCKER, K. 1945. On problem-solving. Psychology Monographs, 58 (5). 
GLUCKSBERG, S., 1962. The influence of strength of drive on functional fixedness and perceptual recognition. Journal of experimental psychology, (63), p.3641.

CROSS, N. 1999. Natural intelligence in design. Design Studies, v. 20, n. 1, p. 2539.

GLUCKSBERG, S. \& WEISBERG, R. W. 1966.V behavior and problem solving: some effects of labeling in a functiona fixedness problem. Journal of Experimental Psychology, 71 (5),659-664.

GOEL, V. 1995. Sketches of Thought. Cambridge: The MIT Press.

KAVAKLI, M; SCRIVENER, S A R; BALL, L J. 1998. Structure in idea sketching behavior. Design Studies, 19 (4), p. 485-517.

KUTNER, M., NETER, J. \& NACHTSHEIM, C. 2004. Applied linear statistical models. McGraw-Hill/Irwin.

UNCG DCL. 2013. Functional Fixedness: An Obstacle to Innovation. Source http://web.uncg.edu/dcl/courses/psychology-ischool/unit7/unit7 function.asp

SIMON, H. 1996. The Sciences of The Artificial. $3^{\circ}$ edition.Cambridge: The MIT Press.

VERSTIJNEN I M; HENNESSEY J M; LEEUWEN, C van; HAMEL, R; GOLDSCHMIDT, G. 1998. Sketching and creative discovery. Design Studies, 19 (4), p.519-546. 